\title{
Glyco-Engineered Anti-Human Programmed Death-Ligand 1 Antibody Mediates Stronger CD8 T Cell Activation Than Its Normal Glycosylated and Non- Glycosylated Counterparts
}

\author{
Christoph Goletz ${ }^{* \dagger}$, Timo Lischke ${ }^{\dagger}$, Ulf Harnack, Phillip Schiele, Antje Danielczyk, \\ Johanna Rühmann and Steffen Goletz
}

Glycotope GmbH, Berlin, Germany

OPEN ACCESS

Edited by: Giuseppe Sconocchia, Istituto di Farmacologia Traslazionale (IFT), Italy

Reviewed by:

Giulio Cesare Spagnoli, Universität Basel, Switzerland

Giandomenica lezzi,

Universität Basel, Switzerland

${ }^{*}$ Correspondence:

Christoph Goletz

christoph.goletz@glycotope.com

${ }^{t}$ These authors have contributed equally to this work.

Specialty section: This article was submitted to Cancer Immunity and Immunotherapy, a section of the journal Frontiers in Immunology

Received: 09 April 2018 Accepted: 28 June 2018

Published: 16 July 2018

Citation:

Goletz C, Lischke T, Harnack U, Schiele P, Danielczyk A, Rühmann J and Goletz S (2018) Glyco-

Engineered Anti-Human Programmed Death-Ligand 1 Antibody Mediates Stronger CD8 T Cell Activation Than

Its Normal Glycosylated and Non-Glycosylated Counterparts.

Front. Immunol. 9:1614. doi: 10.3389/fimmu.2018.01614
The programmed death 1 (PD-1)/programmed death-ligand 1 (PD-L1) axis plays a central role in suppression of anti-tumor immunity. Blocking the axis by targeting PD-L1 with monoclonal antibodies is an effective and already clinically approved approach to treat cancer patients. Glyco-engineering technology can be used to optimize different properties of monoclonal antibodies, for example, binding to FcyRs. We generated two glycosylation variants of the same anti-PD-L1 antibody: one bearing core fucosylated N-glycans in its Fc part (92\%) and its de-fucosylated counterpart (4\%). The two glycosylation variants were compared to a non-glycosylated commercially available anti-PD-L1 antibody in various assays. No differences were observed regarding binding to PD-L1 and blocking of this interaction with its counter receptors PD-1 or CD80. The de-fucosylated anti-PD-L1 antibody showed increased FCyRllla binding resulting in enhanced antibody dependent cellular cytotoxicity (ADCC) activity against PD-L1+ cancer cells compared to the "normal"-glycosylated variant. Both glycosylation variants showed no antibody-mediated lysis of B cells and monocytes. The non-glycosylated reference antibody showed no FcyRIlla engagement and no ADCC activity. Using mixed leukocyte reaction it was observed that the de-fucosylated anti-PD-L1 antibody induced the strongest CD8 T cell activation determined by expression of activation markers, proliferation, and cytotoxicity against cancer cells. The systematic comparison of anti-PD-L1 antibody glycosylation variants with different Fc-mediated potencies demonstrates that our glyco-optimization approach has the potential to enhance CD8 T cell-mediated anti-tumor activity which may improve the therapeutic benefit of anti-PD-L1 antibodies.

Keywords: anti-programmed death-ligand 1, antibody, Fc part, glyco-engineering, defucosylation, T cell activation

\section{INTRODUCTION}

The programmed death 1 (PD-1)/programmed death-ligand 1 (PD-L1) axis has a central role in suppression of anti-tumor immunity (1). PD-L1 (also known as CD274 or B7-H1), a B7 family member, is a transmembrane protein broadly expressed not only in hematopoietic cells, such as B and $\mathrm{T}$ lymphocytes and macrophages but also on nonhematopoietic cells $(2,3)$. Typically, PD-L1 
expression is induced during inflammatory conditions, e.g., in presence of interferon gamma $(\operatorname{IFN}-\gamma)(2,3)$. PD-1, the receptor of PD-L1, is a member of the CD28 family expressed on activated T cells (4). Engagement of PD-1 on T cells by PD-L1 leads to their functional suppression evident by decreased cytokine production and proliferation (3). The tissue expression of PD-L1 is essentially involved in mediating peripheral $\mathrm{T}$ cell tolerance (5), whereas PD-L1 expression on APC is decisive for regulating $\mathrm{T}$ cell immune responses in lymphoid tissues (6). In addition to its function as a ligand for PD-1, PD-L1 can additionally bind to CD80 also resulting in inhibition of T cell activation (7).

Tumor-infiltrating T lymphocytes (TILs) express high levels of PD-1 (8). It has also been shown that TILs produce elevated levels of IFN- $\gamma$, which results in upregulation of PD-L1 on the tumor cell surface (9). Thereby, tumor tissues use PD-L1 expression as an escape mechanism from immune surveillance by dampening $\mathrm{T}$ cell activity (10). Unsurprisingly, PD-L1 is widely expressed on a variety of different tumor tissues (10). The role in immune escape is also emphasized by the finding that PD-L1 expression on tumor cells is often associated with poor prognosis observed for several cancer types, e.g., breast (11) and bladder carcinoma (12).

The therapeutic potential of PD-1/PD-L1 blockade has been demonstrated in multiple cancer mouse models $(13,14)$ and in human clinical trials (15-19). Two anti-PD-1 antibodies were approved for different indications in the last 4 years: nivolumab (Bristol-Myers Squibb) and pembrolizumab (Merck \& Co.). Similarly, the following anti-PD-L1 antibodies have recently been approved for specific indications: atezolizumab (MPDL3280A, Genentech), avelumab (EMD Serono and Pfizer), and durvalumab (AstraZeneca). Summarized, these anti-PD-1 and antiPD-L1 antibodies improve the outcome of anti-cancer immune therapies as well as anti-viral therapies (1). Mechanistically, it has been shown that the blockade of co-inhibitory immune checkpoint molecules like PD-1 and PD-L1 increases the T-cellspecific immune response that turns the immune system against the tumor (1). However, although therapies blocking the PD-1/ PD-L1 axis show impressive long lasting efficacies, curative responses are only observed in certain carcinomas and in a subset of patients (1).

The role of the Fc part of anti-PD-1 and anti-PD-L1 antibodies in cancer therapy has been discussed controversially. Antibodies with Fc-mediated effector functions may mediate antibody dependent cellular cytotoxicity (ADCC) against PD-1 and PD-L1 expressing TILs, and thus may significantly change the effects of therapy (20). In the human system, ADCC is mediated via the activating Fc $\gamma$ RIIIa which is prominently expressed on NK cells $(21,22)$. All approved anti-PD-1 antibodies are of the human IgG4 isotype $(15,16)$ having low affinity to FcyRIIIa (22) to avoid Fc-mediated cytotoxic effects. Two of the currently approved anti-PD-L1 antibodies are of the human IgG1 isotype but have modifications in the $\mathrm{Fc}$ region to eliminate $\mathrm{Fc} \gamma \mathrm{R}$ binding and resulting effector functions $(14,23)$. In contrast, one approved PD-L1-targeting antibody (avelumab) is a fully functional human IgG1 designed to mediate ADCC (24). Interestingly, it has recently been shown in a murine tumor model that anti-PD-1/PD-L1 antibodies differ in their Fc $\gamma R$ requirements for optimal activity: Fc $\gamma R$ engagement compromises the anti-tumor activity of anti-PD-1 antibodies, but binding to activating Fc $\gamma \mathrm{R}$ augments the anti-tumor effects of anti-PD-L1 antibodies (13). Therefore, it was suggested that engineering of the Fc part for enhanced binding to activating FcyRs might be a strategy to optimize the anti-tumor activity of anti-PD-L1 antibodies $(13,25)$. Human IgG antibodies typically have two conserved $\mathrm{N}$-linked oligosaccharides, each of which is attached to the asparagine on position 297 of the heavy chain (26). Removal of the total N-glycans results in loss of Fc $\gamma \mathrm{R}$ binding capacity of the antibody (27), whereas removal only of the core fucose from the N-glycans typically leads to increased affinity for FcyRIIIa (21). Thus, we hypothesized that glyco-optimization of anti-PD-L1 antibodies by reduction of the fucosylation degree might be beneficial and result in enhanced therapeutic responses.

Using the human expression platform GlycoExpress we generated an anti-PD-L1 hIgG1 with "normal" N-glycosylation in its $\mathrm{Fc}$ region. In addition, we generated a glyco-engineered variant of the same anti-PD-L1 hIgG1 with reduced core fucosylation. We compared both variants to a non-glycosylated reference antibody with identical antigen binding to PD-L1 but different affinities for Fc $\gamma$ RIIIa which was highest for the glycoengineered anti-PD-L1. Enhanced binding to FcyRIIIa was reflected by an increased capacity to mediate ADCC against $\mathrm{PD}-\mathrm{L}^{+}$cancer cells. However, the normal glycosylated as well as the glyco-engineered anti-PD-L1 antibody mediated no ADCC against PD-L1 expressing B cells and monocytes. Remarkably, the glyco-engineered anti-PD-L1 induced enhanced CD8 T cell activation in a mixed leukocyte reaction (MLR) determined by expression of activation markers, proliferation, and cytotoxicity against cancer cells, suggesting an improved therapeutic benefit.

\section{MATERIALS AND METHODS}

\section{Construction and Production of Anti-PD-L1 Variants}

The variable region for the glycosylated anti-PD-L1 variants is based on the sequence of atezolizumab (Genentech) (23). The antibody sequences of the variable heavy (VH) and light (VL) region were cloned into expression vectors containing sequences for the human constant domains of the IgG1 $\kappa$ light chain and heavy chain (Glycotope), respectively. Both plasmids were co-transfected in two GlycoExpress cell lines (Glycotope) (28) characterized by normal and reduced core fucosylation followed by selection and gene amplification by increasing concentrations of methotrexate (Sigma-Aldrich, \#M8407) and puromycine (Clontech, \#631306). High producing cell clones isolated from semisolid matrix medium by the ClonePix system (Molecular Devices) were expanded and used for production of supernatants in spinner culture flasks or 21 perfusion bioreactors. Antibodies were purified using protein A chromatography on MabSelect Sure (GE-Healthcare, \#29049104) to a monomer content $>98 \%$ and showed no obvious endotoxin-contamination as tested via LAL endotoxin assay (GenScript). 
Atezolizumab as a reference material was purchased from Genentech (PZN\#11306050).

\section{N-Glycan Analytics}

Antibodies were denatured by RapiGest ${ }^{\mathrm{TM}}$ SF (Waters Inc., $\# 186002123)$ and tris-(2-carboxyethyl)phosphine (120 $\mathrm{min}$, $\left.95^{\circ} \mathrm{C}\right) . \quad \mathrm{N}$-acetylglucosamine-linked oligosaccharides were released by enzymatic digestion with Rapid PNGase F (10 min, $55^{\circ} \mathrm{C}$ ) (Waters Inc., \#186007990) followed by fluorescence tagging with RapiFluor-MS reagent (Waters Inc., \#186007989) in dimethylformamide for $5 \mathrm{~min}$ at room temperature (RT). For clean-up of tagged glycans a $\mu$ Elution Plate (HILIC SPE, Waters Inc., \#186002780) was used. Labeled $\mathrm{N}$-glycans were analyzed by LC-MS employing a HILIC phase (Acquity UPLC BEH GLYCAN $1.7 \mu, 2.1 \times 150$ mm; Waters Inc., \#186004742) with an I-class UPLC (Waters Inc.) coupled to a high resolution QTOF mass spectrometer (Impact HD; Bruker Daltonik). Labeled $\mathrm{N}$-glycans are separated using a gradient from $22 \%$ B to $44 \%$ $\mathrm{B}$ within 82 min (mobile phase A: acetonitrile; mobile phase B: $100 \mathrm{mM}$ ammonium formate in $\mathrm{H} 2 \mathrm{O}, \mathrm{pH} 4.4$ ). RapiFluor-MS tagged $\mathrm{N}$-glycans were detected with a fluorescence detector at $265 \mathrm{~nm}$ excitation wavelength and $425 \mathrm{~nm}$ emission wavelength. Fluorescence signals were employed for glycan quantification. Identification of glycan structures was performed by MS and a series of MS/MS experiments using DataAnalysis Software 4.4 (Bruker Daltonik).

\section{Fc $\gamma$ RIIla Binding}

Binding to hFc $\gamma$ RIIIa was assessed using an assay based on the Alpha technology (Perkin Elmer). In brief, serial dilution of test antibody was mixed with $0.5 \mu \mathrm{g} / \mathrm{ml}$ recombinant His-tagged hFcrRIIIa-158-V (Glycotope) for $30 \mathrm{~min}$ at RT using a shaking device. Afterward, $20 \mu \mathrm{g} / \mathrm{ml}$ rabbit-anti-mouse antibody coated acceptor beads and $20 \mu \mathrm{g} / \mathrm{ml} \mathrm{Ni-chelate} \mathrm{donor} \mathrm{beads}$ (both PerkinElmer, \#AS101M) were added and incubated for $1 \mathrm{~h}$ at RT protected from light. All reagents were diluted in AlphaLisa Universal Buffer (PerkinElmer, \#AL001F). Binding of rabbit-anti-mouse antibody coated acceptor beads to FcyRIIIa coupled to donor beads was inhibited by competitive binding of test antibody to FcyRIIIa coupled to donor beads. The disturbed interaction between donor and acceptor beads was assessed by detection of the decreasing chemiluminescence signal quantified by measurement at 520-620 nm in EnSpire 2300 multilabel reader (PerkinElmer).

\section{Enzyme-Linked Immunosorbent Assays (ELISA)}

For the PD-L1 antigen ELISA, plates (Thermo Fisher Scientific, \#442404) were coated overnight at $4^{\circ} \mathrm{C}$ with $0.75 \mu \mathrm{g} / \mathrm{ml} \mathrm{hPD-L1}$ (SinoBiological, \#10084-H08H) dissolved in PBS. After plates were washed with PBS + 0.05\% Tween-20 (Carl Roth, \#9172.2), blocked for $2 \mathrm{~h}$ at RT with PBS + 2\% BSA (Carl Roth, \#8076.3), and washed again, serial dilutions of test antibodies were added and incubated for $1 \mathrm{~h}$ at RT. After washing, binding was detected using an anti-hIgG Fc-POD (Jackson ImmunoResearch, \#109035-098) diluted in PBS + 1\% BSA which was developed with TMB (tebu-bio/BPS Bioscience, \#TMB100-0500) and stopped by
1.25 $\mathrm{M} \mathrm{H}_{2} \mathrm{SO}_{4}$. Fluorescence was measured at 450-620 $\mathrm{nm}$ at an Infinite F200 plate reader (TECAN).

For the PD-1 and CD80 blockade ELISA hPD-L1-Fc (tebubio/BPS Bioscience, \#71104) was used for coating. Test antibodies were incubated in presence of $1 \mu \mathrm{g} / \mathrm{ml}$ PD-1-Biotin (tebu-bio/ BPS Bioscience, \#71109) or $0.5 \mu \mathrm{g} / \mathrm{ml} \mathrm{CD80-Biotin} \mathrm{(tebu-bio/}$ BPS Bioscience, \#71114). Binding was detected using streptavidin-POD (Jackson ImmunoResearch, \#016-030-084) 1:15,000diluted in PBS $+1 \%$ BSA.

\section{Cell Culture, Cell Lines, and Primary Material}

The cell lines 5637 (DSMZ, \#ACC-35), DU-145 (DSMZ, \#ACC261), KHYG-1 (DSMZ, \#ACC-725), Ramos (DSMZ, \#ACC-603), and ZR-75-1 (ATCC, \#CRL-1500) were obtained from the DSMZ or the ATCC. All cell cultures were free of Mycoplasma and maintained in RPMI1640 medium (Biochrom, \#F1215) supplemented with 10\% FCS (Biochrom, \#S0115) and 1\% L-glutamine (Biochrom, \#K0283). KHYG-1 medium additionally contained 10 ng/ml IL-2 (PeproTech, \#200-02). KHYG-1 cells were stably transfected with hFcyRIIIa 158V (KHYG-1-CD16aV), cloned, and maintained in medium containing $25 \mathrm{nmol} / 1$ methotrexate (Sigma-Aldrich, \#M8407).

Human PBMCs were isolated from leukapheresis products (Charité University Hospital Berlin) or commercially available buffy coats (DRK Berlin) of healthy donors via density gradient centrifugation using Biocoll Separating Solution (Biochrom, \#L6113). In case ofleukapheresis products, isolated PBMCs were stored in AIM-V medium (Life Technologies, \#31035025) supplemented with 75\% FCS (Biochrom, \#S0115) and 10\% DMSO (Sigma-Aldrich, \#D2650) in liquid nitrogen for future usage. All leukapheresis donors were informed of the purpose of the donation and gave their written consent prior to the study.

PBMC subpopulations were isolated using magnetic cell separation: monocytes (Invitrogen, \#11350D or Miltenyi Biotec, \#130-096-537), B cells (Invitrogen, \#11351D), and $\mathrm{T}$ cells (Invitrogen, \#11344D).

\section{Cytotoxicity Assays}

The ADCC assay against DU-145 was performed as europium release assay using KHYG-1-CD16aV as effector cells. Briefly, targets were loaded with europium by electroporation (Nucleofector, Lonza) and incubated with a dilution series of test antibody and KHYG-1-CD16aV (effector:target ratio, $10: 1)$ for $5 \mathrm{~h}$ at $37^{\circ} \mathrm{C}$. Europium release was quantified by timeresolved fluorescence (Infinite F200, Tecan). Maximum release was measured after incubation of target cells with Triton X-100 (Sigma-Aldrich, \#T-9284) and spontaneous release was obtained from samples containing only target cells. Percentage of specific lysis was calculated as follows: (experimental - spontaneous)/ (maximum - spontaneous) $\times 100$.

Additionally, B cells or monocytes were used as target cells and therefore stained for $20 \mathrm{~min}$ at $37^{\circ} \mathrm{C}$ with $0.2 \mu \mathrm{M}$ calcein (Sigma-Aldrich, \#C1359). Thereafter, calcein-labeled B cells or monocytes were subjected to a cytotoxicity in vitro assay with KHYG-1-CD16aV effectors (effector:target ratio, 10:1) in 
presence of test antibody and RPMI1640 medium supplemented with $5 \%$ FCS for $4 \mathrm{~h}$ at $37^{\circ} \mathrm{C}$. Anti-CD20 antibody obinutuzumab (Roche, PZN\#10048686) or staurosporine (Sigma-Aldrich, $\#$ S6942) served as positive controls. After $4 \mathrm{~h}$ at $37^{\circ} \mathrm{C}$, cells were stained with 7-AAD (Sigma-Aldrich, \#A9400) and analyzed by flow cytometry. Cytotoxicity against B cells or monocytes was given as relative frequency of $7-\mathrm{AAD}^{+}$of calcein ${ }^{+}$target cells.

\section{Mixed Leukocyte Reaction}

For generation of monocyte-derived dendritic cells (moDCs), monocytes were cultured in MEM Alpha Medium (Thermo Fisher Scientific, \#22571) supplemented with 20\% FCS (Biochrom, $\#$ S0115) and 10\% conditioned medium (supernatant of 5637 cell culture), $250 \mathrm{U} / \mathrm{ml}$ GM-CSF (Gentaur Pharmaceuticals, \#04-RHUGM-CSF), and 500 U/ml IL-4 (PeproTech, \#200-04) for 7 days. After harvesting, moDCs were cultured in 96-well flat bottom plate (TPP, \#92696) together with allogenic T cells at a ratio of $1: 10$ in the presence of $1 \mu \mathrm{g} / \mathrm{ml}$ of test antibodies in RPMI1640 medium (Biochrom, \#F1215) supplemented with 10\% FCS (Biochrom, \#S0115) and 1\% L-glutamine (Biochrom, \#K0283). Either, supernatants were harvested on day 2 for a hIL-2 ELISA (eBioscience/Affimetryx, \#88-7025-77) or cells were harvested on day 5 and subjected to flow cytometric analysis or to a cytotoxicity assay.

Surface staining for flow cytometry was performed with a variety of monoclonal antibodies coupled to fluorophores: $\alpha \mathrm{CD} 3-$ APC-H7 (clone: SK7, \#560176), $\alpha C D 3-B V 711$ (clone: UCHT-1, \#563724), $\alpha \mathrm{CD} 8-\mathrm{BV} 605$ (clone: SK1, \#564115), and $\alpha \mathrm{CD} 8-\mathrm{FITC}$ (clone: RPA-T8, \#555366) were purchased from Becton Dickinson Biosciences. $\alpha$ CD3-PerCPVio700 (clone: REA613,\#130-109-465) was purchased from Miltenyi Biotec. $\alpha C D 4-F I T C$ (clone: RPAT4,\#300538), $\alpha C D 25-P E$ (clone: BC96, \#302606), $\alpha C D 56-B V 711$ (clone: 5.1H11, \#362542), and $\alpha \mathrm{CD} 137$ (4-1BB)-AF647 (clone: 4B4-1, \#309824) were purchased from BioLegend. Dead cells were excluded by 7-AAD (CalBiochem, \#129935) or DAPI (4-,6diamidino-2-phenylindole, Merck, Germany, \#124653 staining for analysis. Surface stained cells were analyzed with a FACS Canto II (Becton Dickinson Biosciences) or Attune NxT (Thermo Fisher Scientific) flow cytometer. Data were evaluated using the FlowJo 10 software (Treestar). Gates for positive markers were set according to isotype controls.

To analyze proliferation, allogenic $\mathrm{T}$ cells were labeled in some cases with CFSE (5-6-CFDA, Invitrogen, \#C1157) before the MLR assay, according to standard protocols.

Cytotoxicity of T cells was determined in an europium release assay as described above using harvested $\mathrm{T}$ cells as effectors and ZR-75-1 as targets (effector:target ratio, 10:1-100:1) in the absence or presence of 13.5 or $40.4 \mu \mathrm{g} / \mathrm{ml}$ of a bispecific antibody binding to a tumor antigen on ZR-75-1 and to CD3 on T cells (Glycotope). The effector:target ratio and the concentration of the bispecific antibody used within each experiment was consistent.

\section{Calculation of Relative Potencies and Statistical Analysis}

Calculation of relative potencies and statistical analyses was performed with Prism 5.04 software (GraphPad Software Inc.).
Relative potency of hFcrRIIIa binding was determined by calculating the half maximal effective concentration (EC50) for the test and reference antibody using a sigmoidal dose-response model with variable slope constraining the values for bottom, top, and Hill slope. Relative potency was calculated as follows: EC50 of reference antibody divided by EC50 of test antibody.

Statistical analysis was performed using One-Way ANOVA and Bonferroni post test. A $p$ value of $<0.05$ was considered significant ${ }^{*} p<0.05 ;{ }^{* *} p<0.01 ;{ }^{* *} p<0.001$; and ${ }^{* * * *} p<0.0001$; $\mathrm{ns}=$ not significant). In case of One-Way ANOVA with repeated measures, Gaussian distribution was confirmed using the Kolmogorov-Smirnov test.

\section{RESULTS}

\section{Generation of a Normal Glycosylated and a Glyco-Engineered Anti-PD-L1 Antibody With Different Fc $\gamma$ RIIla Binding Capacities}

Two of the approved anti-PD-L1 antibodies lack Fc-mediated effector functions due to modifications in the Fc region in order to avoid potential ADCC against PD-L1-expressing effector cells $(14,23)$. However, it was recently shown that the Fc region contributes to the efficacy of anti-PD-L1 antibodies in the way that isotypes with higher affinity to activating $\mathrm{F} c \gamma \mathrm{R}$ mediate increased anti-tumor activity (13) providing us the rationale to investigate if glyco-engineering of anti-PD-L1 antibodies might result in further improvement.

Atezolizumab is a humanized IgG1 antibody which lacks the $\mathrm{N}$-glycosylation site in its Fc region by changing an aspartic acid into alanine at amino acid position 298 (amino acid position 297 according to EU nomenclature) in the heavy chain leading to minimized binding to Fc $\gamma$ Rs (23) (atezolizumab is referred to as non-glycosylated anti-PD-L1 or $\left.\alpha \mathrm{PDL} 1_{\mathrm{NG}}\right)$. Based on the variable regions of atezolizumab, we designed an anti-PD-L1 antibody construct comprising $\mathrm{N}$-glycosylation sites in its $\mathrm{Fc}$ region and expressed it in two different cell lines of the human expression platform GlycoExpress leading to anti-PD-L1 antibody variants with different glycosylation patterns: first, an anti-PD-L1 antibody with core fucosylated N-glycans (referred to as wild-type antiPD-L1 or $\alpha$ PDL1 $1_{\mathrm{WT}}$ ) and second, an anti-PD-L1 antibody with minimized core fucosylation (referred to as glyco-engineered anti-PD-L1 or $\alpha$ PDL1 $1_{\mathrm{GE}}$ ).

To confirm the different glycosylation pattern of $\alpha P D L 1_{W T}$ and $\alpha \mathrm{PDL} 1_{\mathrm{GE}}$ we isolated the $\mathrm{N}$-linked oligosaccharides from both variants and ran mass spectrometric glycan analyses. Both variants had comparable levels of $\mathrm{N}$-glycans bearing galactose, sialic acid, or bisecting $N$-acetylglucosamine. However, an obvious difference was detected in the degree of fucosylation with $92 \%$ for $\alpha \mathrm{PDL} 1_{\mathrm{WT}}$ and only $4 \%$ for $\alpha \mathrm{PDL} 1_{\mathrm{GE}}$ (Table 1 ).

The removal of core fucose from N-glycans of the Fc region typically leads to increased antibody affinity to FcyRIIIa (21). To test for differences in the binding capacities of $\alpha P D L 1_{\mathrm{NG}}$, $\alpha P D L 1_{\mathrm{WT}}$, and $\alpha \mathrm{PDL}_{\mathrm{GE}}$ to hFc $\gamma$ RIIIa, we used the bead-based AlphaScreen technology. The obtained data confirm that $\alpha P D L 1_{\mathrm{GE}}$ shows enhanced binding compared to $\alpha \mathrm{PDL} 1_{\mathrm{WT}}$, while $\alpha P D L 1_{N G}$ completely lacks Fc $\gamma$ RIIIa binding (Figure 1). This is 
reflected by a reduced EC50 value for $\alpha \mathrm{PDL} 1_{\mathrm{GE}}$ compared to $\alpha P D L 1_{\text {WT }}$ and a relative potency of 3.98 demonstrating $\sim$ fourfold enhanced binding to FcrRIIIa (Table S1 in Supplementary Material). Thus, we had three anti-PD-L1 glycosylation variants with different affinities for hFc $\gamma$ RIIIa available for comparative functional in vitro tests.

\section{Antigen Binding of Glyco-Engineered Anti-PD-L1 Antibody Is Comparable to Its Normal and Non-Glycosylated Counterparts}

As prerequisite for subsequent comparison in functional assays we analyzed the antigen binding properties of $\alpha P D L 1_{\mathrm{NG}}$, $\alpha P D L 1_{\mathrm{WT}}$, and $\alpha \mathrm{PDL}_{\mathrm{GE}}$ using ELISA and flow cytometry. Binding to plate-bound PD-L1 (Figure 2A) and blocking of the interaction with PD-1 and CD80 (Figures 2B,C) was comparable for all three variants. Furthermore, a cross-reactivity ELISA revealed an identical binding pattern to PD-L1 from other species (atezolizumab is cross-reactive with mouse, rat, and cynomolgus monkey $\mathrm{PD}-\mathrm{L} 1$ ), whereas no binding to other human B7 family members (PD-L2, CD80, CD86, B7-H3, $\mathrm{B} 7-\mathrm{H} 4$, and $\mathrm{B} 7-\mathrm{H} 5)$ was observed for any of the three variants

TABLE 1 | N-glycan analysis of the anti-PD-L1 variants $\alpha P D L 1 w$ and $\alpha P D L 1_{G E}$

\begin{tabular}{lcccc}
\hline Antibody & $\mathbf{F ~ ( \% )}$ & $\mathbf{B}(\%)$ & $\mathbf{S}>\mathbf{0}(\%)$ & $\mathbf{G}>\mathbf{0}(\%)$ \\
\hline$\alpha P D L 1 \omega T$ & 92 & 2 & 5 & 56 \\
$\alpha P D L 1$ & 3 & 7 & 58
\end{tabular}

The table summarizes the relative molar amounts of individual N-glycan structures to the following main glycan parameters: $F=$ core fucosylated $N$-glycans;

$B=N$-glycans bearing bisecting $N$-acetylglucosamine; $S>0=$ sialylated $N$-glycans;

$\mathrm{G}>\mathrm{O}=$ galactosylated $\mathrm{N}$-glycans.
(Figure S1 in Supplementary Material). An identical cell surface binding pattern of the three anti-PD-L1 variants as determined for the human cell lines DU-145 (PD-L1 $\left.{ }^{+}\right)$and Ramos $\left(\mathrm{PD}-\mathrm{L1}^{-}\right)$by flow cytometry substantiated the ELISA results (Figure S2 in Supplementary Material). Collectively, our data confirm similar PD-L1 binding properties for the three different anti-PD-L1 variants which were expected as they share identical complementary determining regions.

\section{Glyco-Engineered Anti-PD-L1 Antibody Mediates Strong ADCC Against PD-L1+ Cancer Cells, but Not Against B Cells and Monocytes}

Increased affinity to Fc $\gamma$ RIIIa due to reduced core fucosylation typically results in enhanced ADCC (21). In order to test if the observed differences in FcyRIIIa binding translate into increased ADCC activity we compared the three anti-PD-L1 variants in an ADCC assay with PD-L1 ${ }^{+}$DU-145 as targets and a FcyRIIIa-expressing NK cell line as effectors. As expected due to eliminated Fc-effector functions, no ADCC activity was observed in presence of $\alpha \mathrm{PDL} 1_{\mathrm{NG}}$. In contrast, $\alpha \mathrm{PDL} \mathrm{WT}_{\mathrm{W}}$ mediated target cell lysis and the effect was drastically enhanced by $\alpha \mathrm{PDL}_{\mathrm{GE}}$ (Figure 3A).

Since $\alpha P D L_{W T}$ and $\alpha P D L 1_{\mathrm{GE}}$ effectively mediated ADCC against cancer cells, we investigated their ADCC effect on PBMC subsets. We identified B cells and monocytes as PBMC subpopulations partially expressing PD-L1 (Figure S3 in Supplementary Material) and thus tested their sensitivity toward anti-PDL1-mediated ADCC. The positive control obinutuzumab (antiCD20) effectively induced lysis of primary B cells, whereas neither $\alpha P D L 1_{W T}$ nor $\alpha P D L_{G E}$ showed any ADCC effect (Figure $3 \mathbf{B}$ ). Similarly, no obvious lysis of monocytes was induced by both glycosylated anti-PD-L1 variants, whereas the positive control

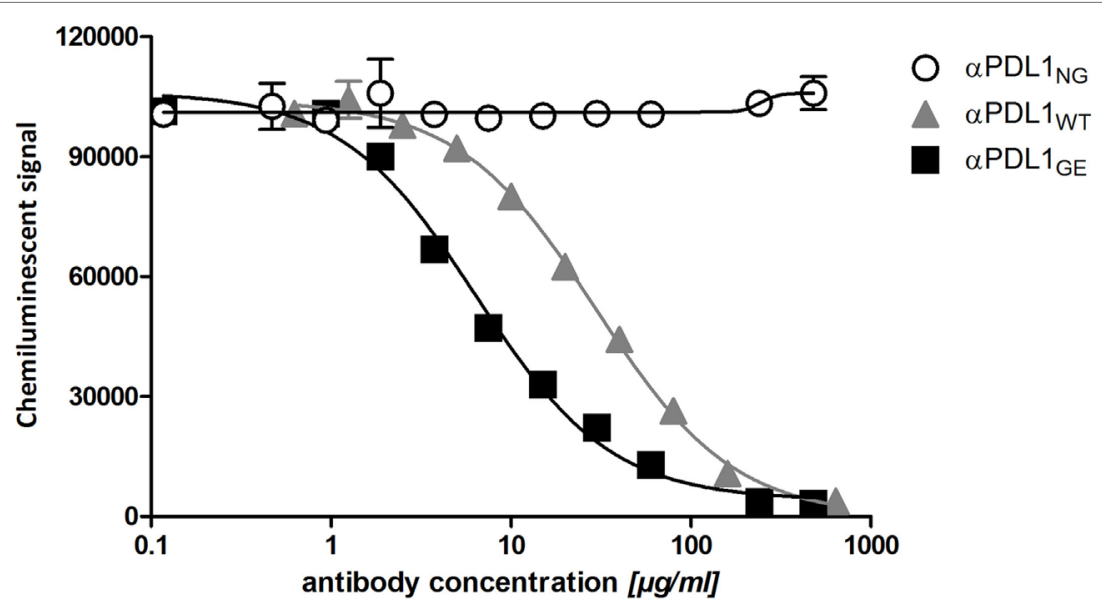

FIGURE 1 | Glyco-engineered anti-human programmed death-ligand 1 (PD-L1) antibody shows an enhanced binding to Fc $\gamma$ RIIla. A competitive FC $\gamma$ RIIla AlphaLISA was performed for the three anti-PD-L1 variants. Thereby the test antibody competes with antibody-conjugated acceptor beads for binding to FcyRIlla-conjugated donor beads. The chemiluminescent signal as a result of close proximity of the donor and acceptor beads was plotted against increasing concentrations of $\alpha \mathrm{PDL} 1_{\mathrm{NG}}$ (open circles), $\alpha P D L 1 w_{\text {T }}$ (gray triangles), and $\alpha \mathrm{PDL} 1_{\mathrm{GE}}$ (black squares). Statistics: mean and SD were plotted in the graph. Data are representative of two independent experiments. 

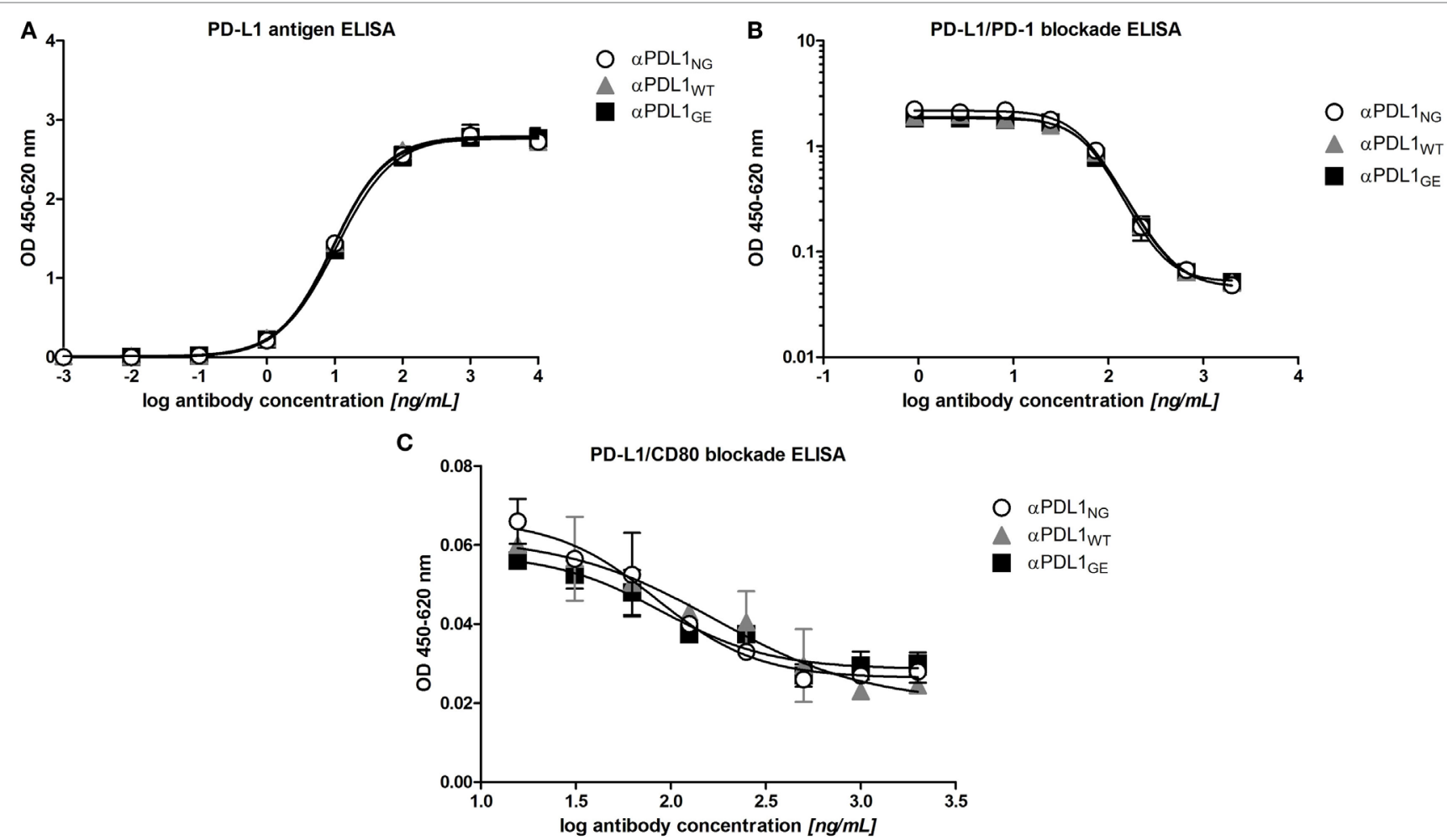

FIGURE 2 | Glyco-engineered anti-human programmed death-ligand 1 (PD-L1) antibody and its normal and non-glycosylated counterparts show comparable antigen binding characteristics. The three anti-PD-L1 variants $\alpha P D L 1_{N G}$ (open circles), $\alpha P D L 1_{W T}$ (gray triangle), and $\alpha P D L 1_{G E}$ (black squares) were tested for PD-L1 antigen binding and their capacity to block interaction with PD-L1 ligands in enzyme-linked immunosorbent assays (ELISA). (A) PD-L1 antigen binding ELISA. $\mathrm{OD}_{450-620}$ values were plotted against increasing concentrations of test antibody to assess binding to plate-bound human PD-L1. (B) Competitive ELISA measuring binding of soluble programmed death 1 to plate-bound PD-L1 in presence of test antibody. OD4 $450-620$ values were plotted against increasing concentrations of test antibody. (C) Competitive ELISA measuring binding of soluble CD80 to plate-bound PD-L1 in presence of test antibody. OD $450-620$ values were plotted against increasing concentrations of test antibody. Statistics: mean and SD were plotted in all graphs. Data are representative of two independent experiments.

staurosporine was effective (Figure 3C). In summary, the glycoengineered anti-PD-L1 variant induced increased ADCC against $\mathrm{PD}-\mathrm{L1}^{+}$cancer cells compared to the normal glycosylated counterpart, but no unwanted ADCC was observed against B cells and monocytes.

\section{Glyco-Engineered Anti-Human PD-L1 Antibody Induces Enhanced CD8 T Cell Activation}

The anti-tumor effect of PD-1/PD-L1 inhibitors is primarily based on restoration of T cell activity (1). An accepted method to investigate the ability of PD-1/PD-L1 checkpoint inhibitors to activate $\mathrm{T}$ cells in vitro is the allogeneic MLR, where moDCs and $\mathrm{T}$ cells from different donors are co-incubated to mimic immunosuppressive effects by the interaction of PD-L1 and PD-1 (14, 29). Figure S4 in Supplementary Material shows the typical phenotype of moDCs used for the MLRs. As responders, T cells were isolated from PBMCs with high purity ranging from 86 to $95 \%$ (determined as $\mathrm{CD}^{+} \mathrm{CD}^{-} 6^{-}$cells). When analyzing the MLR supernatants for IL-2 after 2 days, it was found that all three anti-PD-L1 variants restored the secretion of IL-2 by T cells to a similar extent (Figure 4A). On day 5 of the MLR, CD8 T cells were analyzed for surface expression of CD25 (IL-2R $\alpha$ ) and CD137 (4-1BB, Tnfrsf9) by flow cytometry to determine their activation status. While the addition of $\alpha \mathrm{PDL} 1_{\mathrm{NG}}$ and $\alpha \mathrm{PDL} 1_{\mathrm{WT}}$ to the MLR resulted in minimally elevated CD8 T cell activation compared to the medium control, incubation with $\alpha \mathrm{PDL} 1_{\mathrm{GE}}$ induced significantly enhanced CD8 $\mathrm{T}$ cell activation (Figure $4 \mathbf{B}$ ). The increased activation was accompanied by enhanced proliferation of CD8 T cells (Figure 4C). Interestingly, none of the anti-PD-L1 variants was able to induce an obvious activation of CD4 T cells in terms of upregulation of CD25 and CD137 (Figure 4B) and proliferation (data not shown). Furthermore, we examined the expression of the maturation/activation molecules CD80 (B7-1), CD86 (B7-H2), and HLA-DR on moDCs on day 5 of the MLR (Figure S5 in Supplementary Material). In particular, CD86 and HLA-DR were found to be upregulated in presence of $\alpha P D L 1_{\mathrm{GE}}$ suggesting a more mature status of the moDCs.

Since we observed different results between the anti-PD-L1 variants with respect to $\mathrm{T}$ cell activation marker expression on day 5 but not for IL-2 secretion on day 2, we compared the expression of CD25 on CD8 T cells on day 2 and day 5 (Figure S6-1 in 

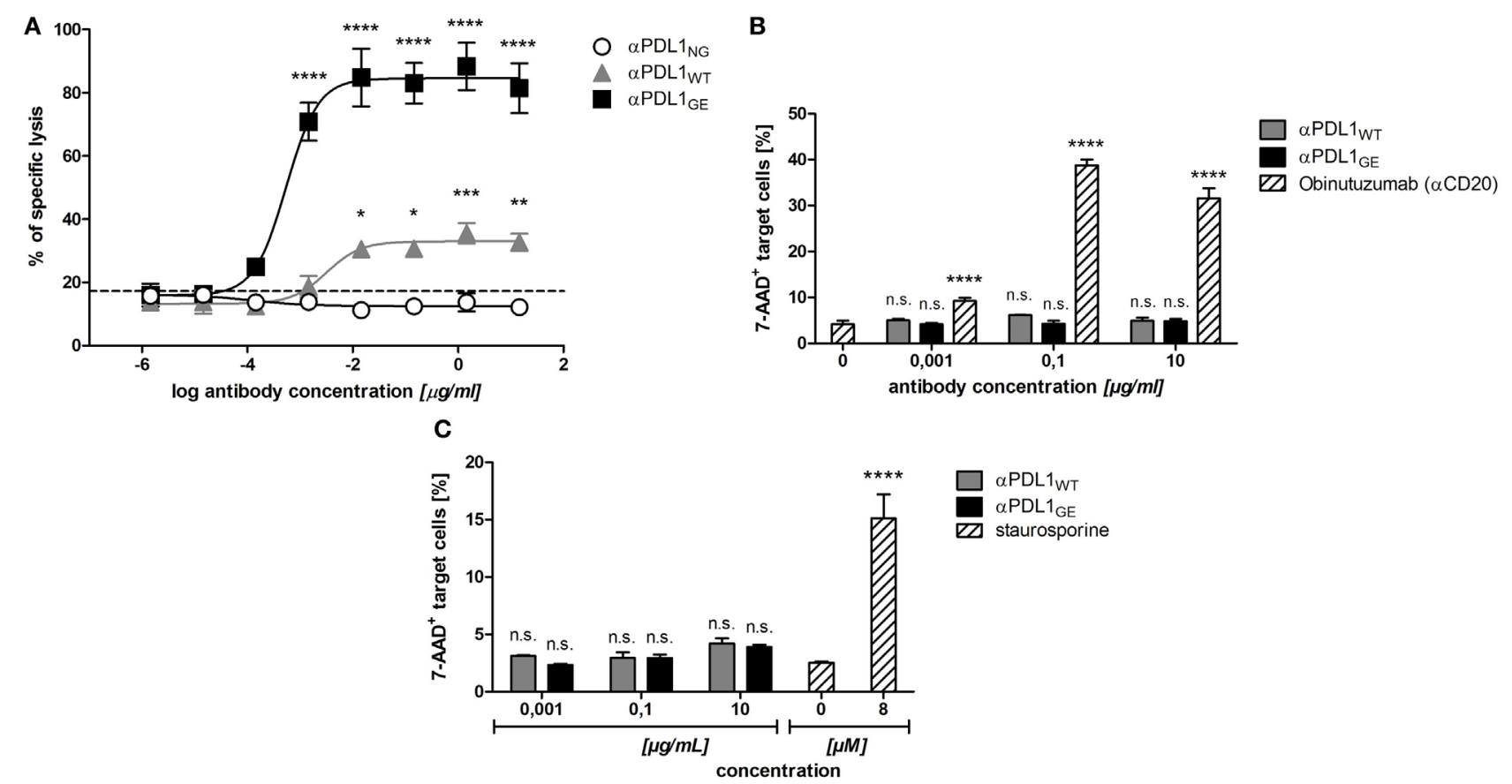

FIGURE 3 | Glyco-engineered anti-human programmed death-ligand 1 (PD-L1) antibody induces strongest NK cell-mediated antibody dependent cellular cytotoxicity (ADCC) against PD-L1+ cancer cells, but none against B cells and monocytes. (A) The NK cell line KHYG-1-CD16aV as effector cells was incubated with europium-loaded PD-L1+ DU-145 cancer cells as target cells in an effector to target ratio of 10:1 in the presence of increasing concentrations of $\alpha$ PDL1 NG $_{\text {(white }}$ circles), $\alpha P D L 1_{W T}$ (gray triangles), or $\alpha P D L 1_{G E}$ (black squares) for $5 \mathrm{~h}$ to determine the lysis of target cells in an in vitro cytotoxicity assay. The percentage of specific target cell lysis is plotted against the antibody concentration used. The dashed line indicates \% of lysis in the medium control. (B,C) The NK cell line KHYG-1CD16aV as effector cells were incubated with calcein-labeled primary B cells (B) or monocytes (C) as target cells in an effector to target ratio of 10:1 in the presence of increasing concentrations of $\alpha \mathrm{PDL} 1_{\mathrm{WT}}$ (gray bars) or $\alpha \mathrm{PDL} 1_{\mathrm{GE}}$ (black bars) for $4 \mathrm{~h}$ to determine the killing of target cells in a flow cytometry based in vitro cytotoxicity assay. The relative frequency of dead $7-\mathrm{AAD}^{+}$of calcein ${ }^{+}$target cells was plotted against the antibody concentration used. As a positive control (striped bars) either obinutuzumab ( $\alpha \mathrm{CD} 20)$ was used to induce B cell lysis or staurosporine was used to induce monocyte lysis. Statistics: mean and SD were plotted in all graphs. Data are representative of two independent experiments. Significance was tested against the medium control $\left({ }^{\star} p<0.05 ;{ }^{* \star} p<0.01 ;{ }^{* \star} p<0.001\right.$; and ${ }^{\star \star \star \star} p<0.0001$. Abbreviation: ns., not significant).

Supplementary Material). Although overall CD8 T cell activation was obviously higher on day 5 compared to day 2 , the advantage of $\alpha \mathrm{PD}-\mathrm{L} 1_{\mathrm{GE}}$ was detectable on both days. In addition, Figure S6-2 and Table S2 in Supplementary Material illustrates that the advantage in CD8 $\mathrm{T}$ cell activation induced by $\alpha \mathrm{PDL} 1_{\mathrm{GE}}$ is present over a range of different antibody concentrations and observed using PBMCs or isolated T cells from further donors.

To confirm these differences in $\mathrm{T}$ cell activation in a more physiological setting, MLRs were performed in the presence of different cancer cell lines. The head and neck cancer cell line HSC-4, the breast cancer line ZR-75-1, and Ramos originally derived from B-cell lymphoma, respectively, were added on day 0 to the MLR (T cells:moDC: cancer cells =100:10:1). Measuring CD25 expression revealed that the presence of HSC-4 and ZR-75-1 had no obvious effect on the CD8 $\mathrm{T}$ cell activation, whereas Ramos cells appear to have some suppressive impact (Figure 5).

In summary, while a normal glycosylated variant of anti-PD$\mathrm{L} 1$ is able to induce $\mathrm{T}$ cell activation to a similar level compared to the non-glycosylated antibody, the glyco-engineered variant results in robustly enhanced CD8 $\mathrm{T}$ cell activation.

\section{Increased T Cell Activation by Glyco- Engineered Anti-PD-L1 Antibody Translates Into Higher Cytotoxicity Against Cancer Cells}

We also addressed the question, if the enhanced $T$ cell activation induced by the glyco-engineered anti-PD-L1 antibody has an influence on $\mathrm{T}$ cell effector functions, in particular cytotoxicity against cancer cells. For that purpose, $\mathrm{T}$ cells which were activated in a MLR in absence or presence of $\alpha P D L 1_{\mathrm{NG}}, \alpha P D L 1_{\mathrm{WT}}$, and $\alpha P D L 1_{\mathrm{GE}}$ were harvested and analyzed for their cytotoxic capacity using a europium release assay. Therefore, we selected ZR-75-1 as target cells because they were not sensitive for antiPD-L1-mediated ADCC (Figure S7 in Supplementary Material). Since we assumed that $\mathrm{T}$ cells isolated from the MLR were not particularly reactive to ZR-75-1 due to lack of specificity, we additionally tested their cytotoxicity in presence of a bispecific antibody binding to a tumor antigen on ZR-75-1 and to CD3 on $\mathrm{T}$ cells ensuring close proximity between target and effector cell. In both conditions, in absence and presence of the bispecific antibody, the cytotoxicity of pre-activated $\mathrm{T}$ cells was increased 


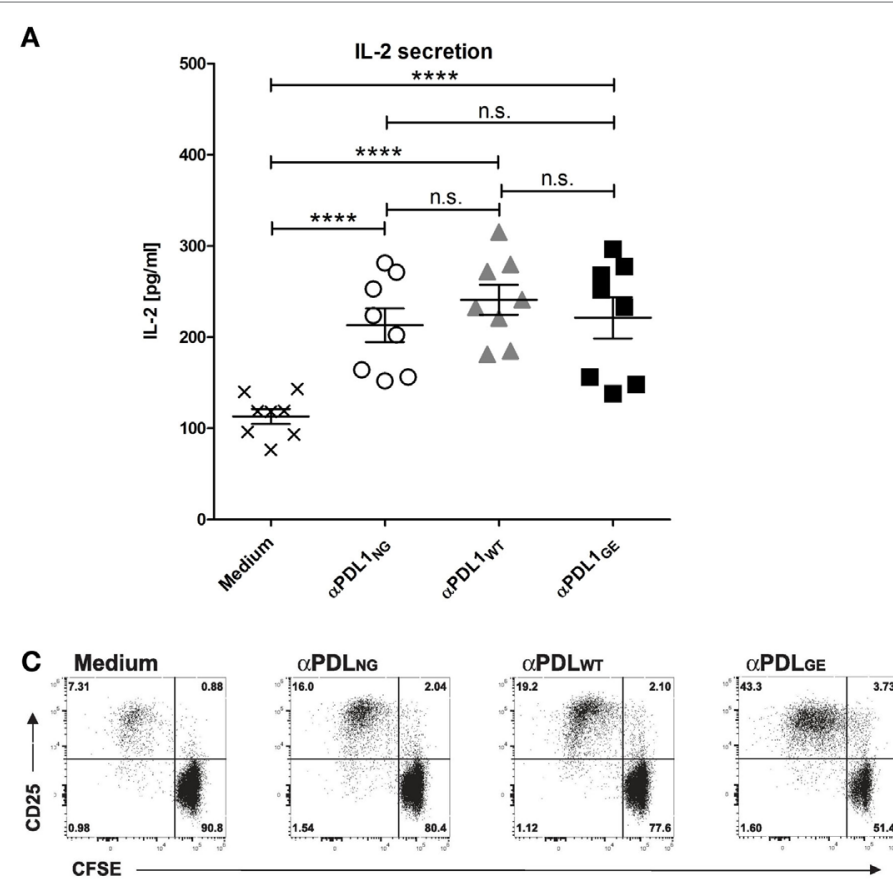

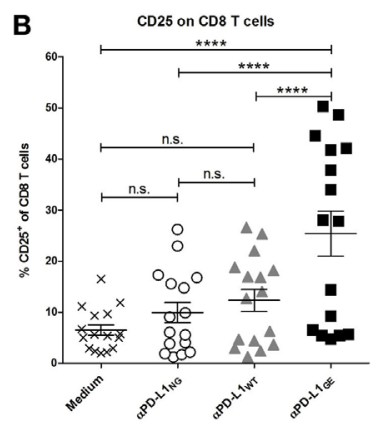
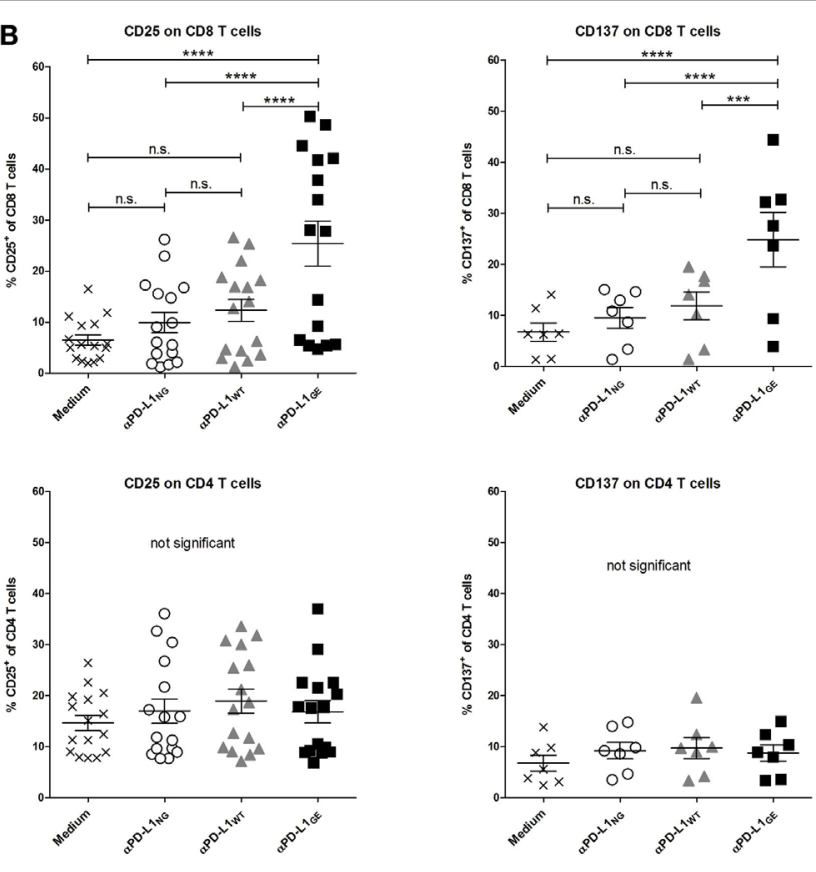

FIGURE 4 | Glyco-engineered anti-human programmed death-ligand 1 (PD-L1) antibody induces strong CD8 T cell activation in a mixed leukocyte reaction. The three anti-PD-L1 variants $\alpha P D L 1_{N G}$ (open circles), $\alpha P D L 1_{W T}$ (gray triangles), and $\alpha P D L 1$ GE (black squares) were tested for their effect on $T$ cell activation in a mixed leukocyte reaction (MLR). The medium control (black crosses) served as a negative control. T cells as responder cells were isolated from a single healthy donor (donor A). Monocyte-derived dendritic cells as stimulator cells were generated from different healthy donors. (A) IL-2 enzyme-linked immunosorbent assays on day 2 of MLR. The determined concentrations of IL-2 in the culture supernatants were plotted. (B) The activation status of CD8 and CD4 T cells in the MLR was determined on day 5 by flow cytometric analysis. The relative frequencies of CD25+ and CD137+ in CD8 and CD4 T cells were plotted. (C) The proliferation of CFSE-labeled CD8 T cells in the MLR was determined on day 5 by CFSE dilution measured by flow cytometric analysis. Representative plots of CD25 expression and CFSE signal intensity of CD8 T cells are shown. Statistics for (A,B): besides individual data points $(n=8$ for IL-2 secretion, $n=16$ for CD25 expression, and $n=7$ for CD137), mean and SEM were plotted in all graphs ( ${ }^{\star} p<0.05$; ${ }^{\star \star} p<0.01 ;{ }^{\star \star \star} p<0.001$; and ${ }^{\star \star \star \star} p<0.0001$. Abbreviation: ns, not significant).

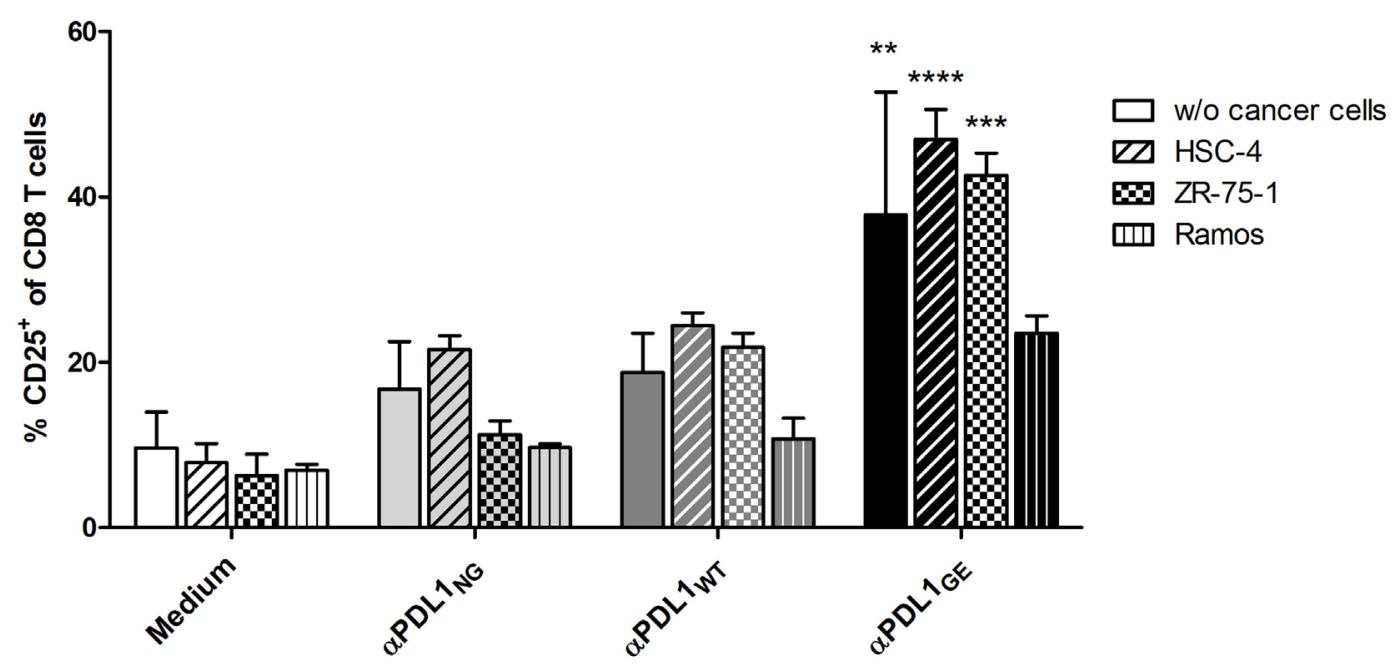

FIGURE 5 | Glyco-engineered anti-human programmed death-ligand 1 (PD-L1) antibody induces increased CD8 T cell activation in presence of cancer cells. The three anti-PD-L1 variants $\alpha P D L 1_{N G}$ (light gray bar), $\alpha P D L 1 w$ (dark gray bar), and $\alpha P D L 1$ GE (black bar) were tested for their effect on T cell activation (donor A) in allogeneic mixed leukocyte reaction (MLRs) in absence or presence of the cancer cell lines HSC-4 (horizontal stripes), ZR-75-1 (plaid), and Ramos (vertical stripes). MLR without addition of test antibody (medium; white bar) served as negative control. The relative frequencies of CD25+ in CD8 T cells were plotted. Statistics: mean and SD were plotted in all graphs. Data are representative of two independent experiments. Significance was tested against the medium control without presence of cancer wells $\left({ }^{*} p<0.05 ;{ }^{* *} p<0.01 ;{ }^{* \star *} p<0.001\right.$; and $\left.{ }^{* \star * *} p<0.0001\right)$. 
compared to the medium control, and the strongest pre-activation due to treatment with $\alpha \mathrm{PDL} 1_{\mathrm{GE}}$ resulted in the highest cytotoxicity (Figure 6; Figure S8 in Supplementary Material).

\section{DISCUSSION}

Programmed death-ligand 1 blockade using therapeutic antiPD-L1 antibodies is a promising approach in the therapy of a variety of cancers as it interferes with a co-inhibitory checkpoint pathway on TILs and thereby enhances anti-tumor immunity (1). In line with findings for other immunomodulatory antibodies, e.g., anti-CTLA-4 (30), recent preclinical data obtained in a syngeneic mouse tumor model highlight the contribution of the Fc domain for the functionality of anti-PD-L1 antibodies and suggests that the anti-tumor response of anti-PD-L1 antibodies is at least partially dependent on engagement of activating Fc $\gamma$ Rs (13). Thus, we generated an anti-PD-L1 of hIgG1 isotype based on the variable regions of non-glycosylated atezolizumab bearing "normal" core fucosylated $\mathrm{N}$-glycans in its $\mathrm{Fc}$ region and a further glyco-engineered variant with fucose-reduced $\mathrm{N}$-glycans. When comparing the non-glycosylated, the normal glycosylated and the glyco-engineered anti-PD-L1 variants we observed identical antigen binding, but enhanced Fc $\gamma$ RIIIa binding for $\alpha \mathrm{PDL} 1_{\mathrm{GE}}>\alpha \mathrm{PDL} 1_{\mathrm{WT}}>\alpha \mathrm{PDL} 1_{\mathrm{NG}}$. Accordingly, NK cell-mediated ADCC against a PD- $\mathrm{L}^{+}$cancer cell line was enhanced for $\alpha \mathrm{PDL} 1_{\mathrm{GE}}>\alpha \mathrm{PDL} 1_{\mathrm{WT}}>\alpha \mathrm{PDL} 1_{\mathrm{NG}}$. In contrast, no ADCC against PD-L1 expressing B cells and monocytes could be detected. Surprisingly, testing of these anti-PD-L1 variants in a MLR revealed increased CD8 T cell activation potential for $\alpha P D L 1_{\mathrm{GE}}>\alpha \mathrm{PDL} 1_{\mathrm{WT}} \geq \alpha \mathrm{PDL} 1_{\mathrm{NG}}$ determined by surface expression of CD25 and CD137, proliferation as well as cytotoxicity against cancer cells.

Tumor cell killing via ADCC is an important mechanism of several therapeutic antibodies including rituximab and cetuximab as demonstrated in human in vitro systems $(31,32)$ and as implicated by several clinical studies $(33,34)$. Avelumab which is to our knowledge a normal glycosylated anti-PD-L1 antibody has been shown to mediate ADCC in in vitro studies (24). Similarly, we generated the normal glycosylated anti-PD-L1 antibody to allow for mediation of ADCC via a functional Fc part. For our glyco-engineered anti-PD-L1 antibody we found an enhanced NK cell-mediated ADCC against PD-L1 ${ }^{+}$cancer cells compared to the normal glycosylated variant, which is in line with the well-established superior ADCC capacity of several glyco-engineered antibodies (e.g., anti-CD20, anti-EGFR) $(32,35)$. However, an enhanced capability for ADCC involves the risk of unwanted cytotoxic effects on PD-L1-expressing PBMC. Avelumab is described to mediate no obvious lysis of PBMCs as shown by in vitro cytotoxicity assays and by the fact that patients treated with avelumab had no significant changes in their peripheral immune cell profile $(24,36)$. In addition, avelumab has a manageable safety profile in the clinic (18) as it is also reported for the anti-PD-L1 antibodies which are unable to mediate $\operatorname{ADCC}(17,19)$. In line with literature data (2), we identified B cells and monocytes as PBMC subpopulations partially expressing PD-L1. Subsequent testing revealed
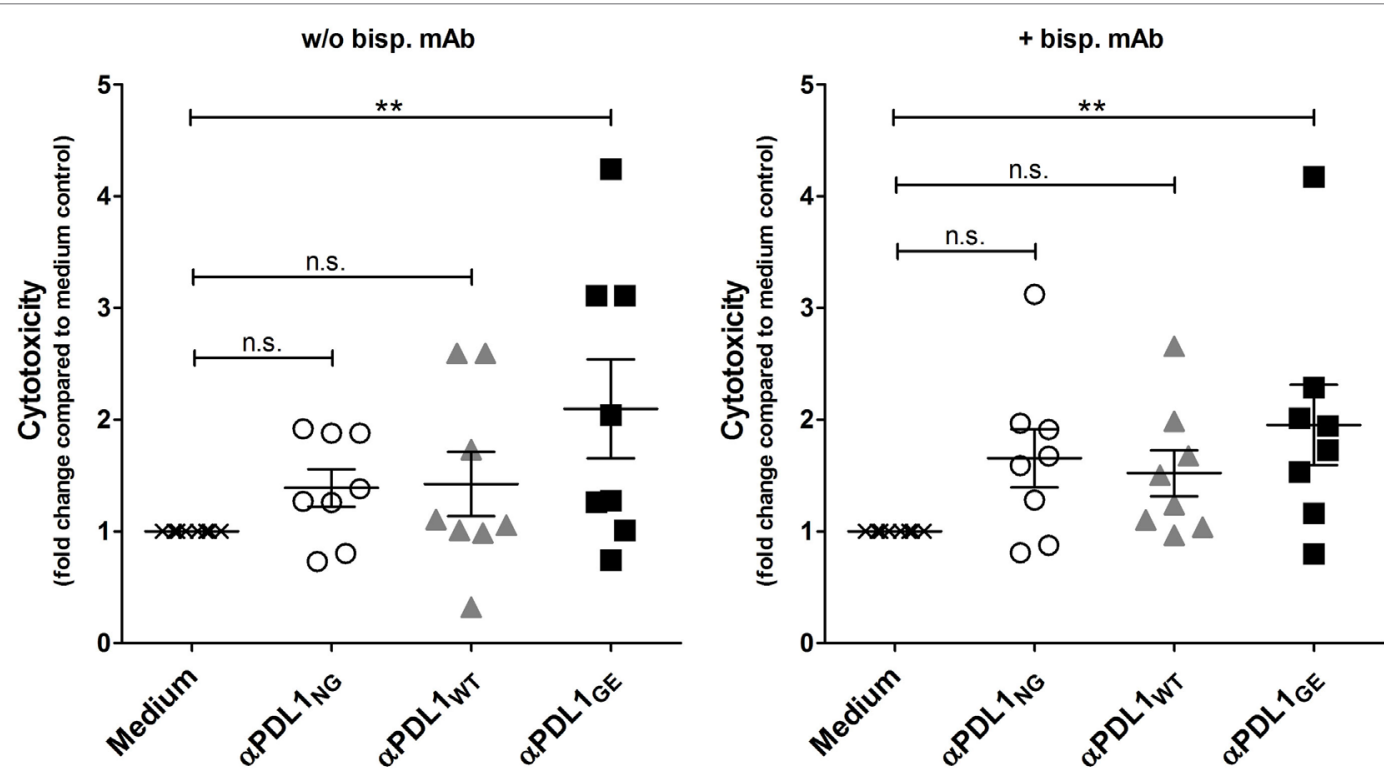

FIGURE 6 | $\alpha \mathrm{PDL} 1_{\mathrm{GE}}$-dependent enhancement of CD8 ${ }^{+} \mathrm{T}$ cell activation results in increased cytotoxicity against cancer cells. T cells of two different donors (donor $\mathrm{B}$ and donor $\mathrm{C}$ ) pre-activated in a mixed leukocyte reaction (MLR) for 5 days in the presence of $\alpha \mathrm{PDL} 1_{\mathrm{NG}}$ (open circles), $\alpha \mathrm{PDL} 1_{\mathrm{wT}}$ (gray triangles), and $\alpha P D L 1_{G E}$ (black squares) were harvested and incubated with europium-loaded ZR-75-1 cells for $5 \mathrm{~h}$ to determine the lysis of target cells in an in vitro cytotoxicity assay. T cells isolated from MLR without addition of test antibody (medium; black crosses) served as negative control. The cytotoxicity assay was performed in absence and presence of a bispecific antibody binding to a tumor antigen on ZR-75-1 and to CD3 on T cells. The fold change in cytotoxicity compared to the medium control is plotted. Statistics: besides individual data points $(n=8)$, mean and SEM were plotted. Significance was tested against the medium control $\left({ }^{\star} p<0.05 ;{ }^{* \star} p<0.01 ;{ }^{* \star} p<0.001\right.$; and $\left.{ }^{* \star \star *} p<0.0001\right)$. 
that neither the normal glycosylated nor the glyco-engineered anti-PD-L1 antibody mediated any measurable lysis of these cells consistent with the results shown for avelumab $(24,36)$. Since the antigen density on the cancer cell surface impacts the anti-PD-L1 antibody mediated ADCC (24), we suppose that the expression level of PD-L1 on the tested PBMC subpopulations is too low for effective lysis of these cells. However, we cannot generally exclude that PD-L1-expressing immune cells will not be targeted by anti-PD-L1 antibodies and for that reason a potential ADCC against immune cells needs to be thoroughly investigated by further tests, e.g., by using preactivated PBMC as targets. Since myeloid-derived suppressor cells (MDSCs) in the tumor microenvironment have increased expression of PD-L1 (37), an antibody dependent depletion of these immune cells might also be beneficial as it is already described by Dahan and colleagues in their syngeneic mouse model (13).

To our knowledge this is the first demonstration that glycoengineering of an anti-PD-L1 antibody results in increased CD8 $\mathrm{T}$ cell activation conferring to an enhanced CD8 T cell cytotoxicity against tumor cells. It is known that removal of fucose from $\mathrm{N}$-glycans of the Fc portion of hIgG primarily results in enhanced binding to Fcy RIIIa (21). In combination with our finding that the tested anti-PD-L1 variants differed with respect to FcyRIIIa but not antigen binding, we assume that binding of the Fc part to FcyRIIIa is causative for the observed differences in the strength of CD8 T cell activation in the MLR. Thus our study provides a further indication in addition to the results of Dahan and colleagues (13) that Fc $\gamma R$ engagement augments the anti-tumor activity of anti-PD-L1 antibodies.

It has been shown that PD-1/PD-L1 blockade results in IL-2 secretion of T cells (29). Interestingly, (using an allogeneic MLR) addition of all three anti-PD-L1 variants heightened the IL-2 release in a similar range. In contrast, CD8 T cell activation (according to surface expression of CD25 and CD137) was most pronounced in the presence of the glyco-engineered anti-PD-L1 antibody. IL-2 is typically produced by T helper cells (also referred to as CD4 T cells), although it can also be produced by cytotoxic T cells (also referred to as CD8 T cells) but to a lesser extent. Since we did not observe obvious differences in IL-2 secretion and in CD4 T cell activation regarding the expression of CD25 and CD137 between the different glycosylation variants, we assume that IL-2 detected in the MLR was primarily secreted by CD4 T cells and that glycoengineering has a stronger effect on CD8 $\mathrm{T}$ cell activation than on CD4 T cells.

Studies in syngeneic mouse models revealed that engagement of activating FcyRs by anti-PD-L1 antibodies augments their anti-tumor activity and that this effect was partially mediated by depletion of PD-L1-expressing MDSC (13). Similar observations were reported for anti-CTLA-4, anti-GITR, and anti-OX40 antibodies in murine systems demonstrating that binding to activating FcyR results in depletion of intra-tumoral Tregs and contributes to anti-tumor activity $(30,38-40)$. Simpson and colleagues identified FcyRIV-expressing macrophages as potential effector cells mediating ADCC against CTLA-4-expressing intra-tumoral Tregs (39). Human FcyRIIIa is the ortholog of murine Fc $\gamma$ RIV (22) suggesting that Fc $\gamma$ RIIIa-bearing immune cells might represent corresponding effector cells in the human system. Indeed, melanoma patients responding to anti-CTLA-4 therapy (ipilimumab, hIgG1) displayed increased levels of circulating nonclassical FcyRIIIa-expressing monocytes able to lyse Tregs ex vivo, and additionally showed a decrease in intra-tumoral Tregs after treatment with concurrent presence of Fc $\gamma$ RIIIa-expressing M1-like macrophages in the tumor (41). Monocytes might also play a role in our MLR experiments as it was set up with purified in vitro differentiated monocyte-derived DC (moDC) as stimulators and potentially some remaining undifferentiated $\mathrm{Fc} \gamma \mathrm{RIIIa}^{+}$monocytes might eliminate PD-L1 ${ }^{+}$ suppressor cells and thereby enhance the response. Furthermore, monocytes might particularly act as cytotoxic cells lysing PD-L1+ suppressor cells in the MLR assays where total PBMCs were used as responder cells.

Since the glyco-engineered variant of anti-PD-L1 is generally capable of eliciting ADCC, also other Fcy RIIIa+ immune cells besides monocytes might mediate ADCC-dependent depletion of PD-L1+ cells in the MLR setting and thereby contribute to the enhanced CD8 T cell activation. Beside NK cells, NKT cells and $\gamma \delta$-T cells are described to express Fc $\gamma$ RIIIa and to mediate $\operatorname{ADCC}(42,43)$. This could have a significant impact on the results in the MLR assays where whole PBMCs have been used as responders (NK cells, NKT cells, and $\gamma \delta$-T cells are present), but also when using isolated $\mathrm{T}$ cells (NKT cells and $\gamma \delta$-T cells still present). A systematic comparison of using isolated $\alpha \beta$-T cells \pm defined Fc $\gamma \mathrm{RIIIa}^{+}$immune cell subpopulations versus total PBMCs of the same donor as responders would address this issue, but was beyond the scope of this work.

Another possible explanation is that an enhanced occupancy of Fc $\gamma$ Rs by the glyco-engineered anti-PD-L1 variant results in a better maturation of moDCs followed by enhanced activation of CD8 T cells. Supporting this explanation, it was shown that anti-EGFR antibodies can directly bind to FcyR on monocytes leading to upregulation of co-stimulatory molecules (44), but also that anti-EGFR antibodies can initiate $\mathrm{T}$ cell responses via Fc-dependent activation of NK cells inducing DC maturation $(44,45)$. Further, $\gamma \delta$-T cells have been shown to secrete IFN- $\gamma$ after Fc $\gamma$ RIIIa engagement of antibodies (42), and thereby induce DC maturation resulting in enhanced CD8 T cell activation (46). In line with these studies, we observed an upregulated expression of the maturation markers CD86 and HLA-DR on the moDCs in presence of the glyco-engineered anti-PD-L1 antibody.

Two of the approved anti-PD-L1 antibodies were specifically designed to eliminate ADCC activity $(14,23)$, only one has Fc-mediated functionality (24) thereby combining blockade of the PD-1/PD-L1 axis and a limited ADCC activity in one molecule. Both modes of action might act synergistically. Blocking the PD-1/PD-L1 axis can enhance general anti-tumor activity of NK cells expressing PD-1 including direct cytotoxicity and ADCC against tumor cells $(47,48)$. The efficacy of antibodies targeting the PD-1/PD-L1 axis seems to be dependent on PD-L1 expression on the tumor (19). NK cells, but also $\gamma \delta$-T cells, 
activated through their Fc $\gamma$ Rs secrete IFN- $\gamma$ (42) which in turn can upregulate PD-L1 expression on cancer cells (9). Since our data show that a glyco-engineered anti-PD-L1 antibody even combines a full blockade of the PD-1/PD-L1 axis with an increased CD8 T cell activation and an enhanced ADCC activity, the synergism between these modes of action might be even stronger. Furthermore, glyco-engineering of antibodies is expected to lead to a broader patient coverage, since enhanced Fc $\gamma$ RIIIa binding is also observed for the low-affinity variant Fc $\gamma$ RIIIa $158 \mathrm{~F}$ of the receptor which is homozygous in $\sim 42 \%(\mathrm{~F} / \mathrm{F})$ and heterozygous in $\sim 50 \%(\mathrm{~F} / \mathrm{V})$ of healthy Caucasians $(35,49)$.

In summary, the present study demonstrates that glycooptimization due to defucosylation has the potential to improve the therapeutic benefit of anti-PD-L1 antibodies. A glycoengineered anti-PD-L1 antibody could be clinically developed as a monotherapeutic drug or as a combination therapy. Several clinical trials are underway for anti-PD-L1 antibodies in combination with other drugs, for example, with antibodies targeting stimulatory checkpoint molecules, with VEGF inhibitors or with different tyrosine kinase inhibitors (50). Our novel concept is the combination of a glyco-engineered anti-PD-L1 antibody with a second specificity directed against a tumor-specific antigen composed of a bispecific antibody construct, which would have the advantage that release of the PD-1/PD-L1 axis would be focused on the tumor site thereby potentially reducing side effects and increasing efficacy. The development and characterization of such a bispecific anti-PDL1 antibody is currently ongoing.

\section{REFERENCES}

1. Baumeister SH, Freeman GJ, Dranoff G, Sharpe AH. Coinhibitory pathways in immunotherapy for cancer. Annu Rev Immunol (2016) 34(1):539-73. doi:10.1146/annurev-immunol-032414-112049

2. Dong H, Zhu G, Tamada K, Chen L. B7-H1, a third member of the b7 family, co-stimulates T-cell proliferation and interleukin-10 secretion. Nat Med (1999) 5(12):1365-9. doi:10.1038/70932

3. Freeman GJ, Long AJ, Iwai Y, Bourque K, Chernova T, Nishimura H, et al. Engagement of the PD-1 immunoinhibitory receptor by a novel b7 family member leads to negative regulation of lymphocyte activation. J Exp Med (2000) 192(7):1027-34. doi:10.1084/jem.192.7.1027

4. Ishida Y, Agata Y, Shibahara K, Honjo T. Induced expression of PD-1, a novel member of the immunoglobulin gene superfamily, upon programmed cell death. EMBO J (1992) 11(11):3887.

5. Keir ME, Liang SC, Guleria I, Latchman YE, Qipo A, Albacker LA, et al. Tissue expression of pd-11 mediates peripheral T cell tolerance. J Exp Med (2006) 203(4):883-95. doi:10.1084/jem.20051776

6. Mueller SN, Vanguri VK, Ha SJ, West EE, Keir ME, Glickman JN, et al. Pd-11 has distinct functions in hematopoietic and nonhematopoietic cells in regulating $\mathrm{T}$ cell responses during chronic infection in mice. J Clin Invest (2010) 120(7):2508-15. doi:10.1172/JCI40040

7. Butte MJ, Keir ME, Phamduy TB, Sharpe AH, Freeman GJ. Programmed death-1 ligand 1 interacts specifically with the b7-1 costimulatory molecule to inhibit T cell responses. Immunity (2007) 27(1):111-22. doi:10.1016/j. immuni.2007.05.016

8. Ahmadzadeh M, Johnson LA, Heemskerk B, Wunderlich JR, Dudley ME, White DE, et al. Tumor antigen-specific CD8 T cells infiltrating the tumor express high levels of PD-1 and are functionally impaired. Blood (2009) 114(8):1537-44. doi:10.1182/blood-2008-12-195792

9. Taube JM, Anders RA, Young GD, Xu H, Sharma R, McMiller TL, et al. Colocalization of inflammatory response with b7-h1 expression in human

\section{AUTHOR CONTRIBUTIONS}

Conception and design of project: CG, TL, JR, AD, and SG. Development of methodology: CG, JR, and TL. Acquisition of data: CG and TL. Analysis and interpretation of data: CG, TL, and UH. Drafting and revising the article: CG, TL, UH, PS, JR, $\mathrm{AD}$, and SG.

\section{ACKNOWLEDGMENTS}

For expert technical assistance we thank Carolin Lange, Stephanie Plassmann, Lisa Weiss, and Sigrid Wiese. We also thank Doreen Weigelt, Nathalie Rigal, Marion Schlangstedt, Julia Kallenbach, Rainer Stahn, Steffen Kreye, Anke Flechner, Robert Friedrich, Ariane Wenzel, Sven Bahrke, and Robert Wilmanowski for discussion and helpful advices.

\section{FUNDING}

This work was supported by Glycotope $\mathrm{GmbH}$ who provided the anti-PD-L1 antibodies and financial support for the conduct of experiments.

\section{SUPPLEMENTARY MATERIAL}

The Supplementary Material for this article can be found online at https://www.frontiersin.org/articles/10.3389/fimmu.2018.01614/ full\#supplementary-material.

melanocytic lesions supports an adaptive resistance mechanism of immune escape. Sci Transl Med (2012) 4(127):ra37-127. doi:10.1126/scitranslmed. 3003689

10. Dong H, Strome SE, Salomao DR, Tamura H, Hirano F, Flies DB, et al. Tumor-associated b7-h1 promotes T-cell apoptosis: a potential mechanism of immune evasion. Nat Med (2002) 8(8):793-800. doi:10.1038/nm730

11. Muenst S, Schaerli A, Gao F, Däster S, Trella E, Droeser R, et al. Expression of programmed death ligand 1 (pd-11) is associated with poor prognosis in human breast cancer. Breast Cancer Res Treat (2014) 146(1):15-24. doi:10.1007/ s10549-014-2988-5

12. Boorjian SA, Sheinin Y, Crispen PL, Farmer SA, Lohse CM, Kuntz SM, et al. T-cell coregulatory molecule expression in urothelial cell carcinoma: clinicopathologic correlations and association with survival. Clin Cancer Res (2008) 14(15):4800-8. doi:10.1158/1078-0432.CCR-08-0731

13. Dahan R, Sega E, Engelhardt J, Selby M, Korman AJ, Ravetch JV. Fcgammars modulate the anti-tumor activity of antibodies targeting the PD-1/PD-11 axis. Cancer Cell (2015) 28(3):285-95. doi:10.1016/j.ccell.2015.08.004

14. Stewart R, Morrow M, Hammond SA, Mulgrew K, Marcus D, Poon E, et al. Identification and characterization of medi4736, an antagonistic anti-pd-11 monoclonal antibody. Cancer Immunol Res (2015) 3(9):1052-62. doi:10.1158/2326-6066.CIR-14-0191

15. Hamid O, Robert C, Daud A, Hodi FS, Hwu W-J, Kefford R, et al. Safety and tumor responses with lambrolizumab (anti-PD-1) in melanoma. N Engl J Med (2013) 369(2):134-44. doi:10.1056/NEJMoa1305133

16. Weber JS, DAngelo SP, Minor D, Hodi FS, Gutzmer R, Neyns B, et al. Nivolumab versus chemotherapy in patients with advanced melanoma who progressed after anti-ctla-4 treatment (checkmate 037): a randomised, controlled, open-label, phase 3 trial. Lancet Oncol (2015) 16(4):375-84. doi:10.1016/S1470-2045(15)70076-8

17. Rosenberg JE, Hoffman-Censits J, Powles T, van der Heijden MS, Balar AV, Necchi A, et al. Atezolizumab in patients with locally advanced and metastatic urothelial carcinoma who have progressed following treatment with platinum-based 
chemotherapy: a single-arm, multicentre, phase 2 trial. Lancet (2016) 387(10031):1909-20. doi:10.1016/S0140-6736(16)00561-4

18. Kaufman HL, Russell J, Hamid O, Bhatia S, Terheyden P, DAngelo SP, et al. Avelumab in patients with chemotherapy-refractory metastatic Merkel cell carcinoma: a multicentre, single-group, open-label, phase 2 trial. Lancet Oncol (2016) 17(10):1374-85. doi:10.1016/S1470-2045(16)30364-3

19. Massard C, Gordon MS, Sharma S, Rafii S, Wainberg ZA, Luke J, et al. Safety and efficacy of durvalumab (medi4736), an anti-programmed cell death ligand-1 immune checkpoint inhibitor, in patients with advanced urothelial bladder cancer. J Clin Oncol (2016) 34(26):3119-25. doi:10.1200/JCO.2016.67.9761

20. Chen DS, Irving BA, Hodi FS. Molecular pathways: next-generation immunotherapy - inhibiting programmed death-ligand 1 and programmed death-1. Clin Cancer Res (2012) 18(24):6580-7. doi:10.1158/1078-0432.CCR-12-1362

21. Masuda K, Kubota T, Kaneko E, Iida S, Wakitani M, Kobayashi-Natsume Y, et al. Enhanced binding affinity for FCgammaRIIIa of fucose-negative antibody is sufficient to induce maximal antibody-dependent cellular cytotoxicity. Mol Immunol (2007) 44(12):3122-31. doi:10.1016/j.molimm.2007.02.005

22. Bruhns P. Properties of mouse and human IgG receptors and their contribution to disease models. Blood (2012) 119(24):5640-9. doi:10.1182/ blood-2012-01-380121

23. Herbst RS, Soria JC, Kowanetz M, Fine GD, Hamid O, Gordon MS, et al. Predictive correlates of response to the anti-pd-11 antibody mpdl3280a in cancer patients. Nature (2014) 515(7528):563-7. doi:10.1038/nature14011

24. Boyerinas B, Jochems C, Fantini M, Heery CR, Gulley JL, Tsang KY, et al. Antibody-dependent cellular cytotoxicity activity of a novel anti-pd-11 antibody avelumab (msb0010718c) on human tumor cells. Cancer Immunol Res (2015) 3(10):1148-57. doi:10.1158/2326-6066.CIR-15-0059

25. Offringa R, Glennie MJ. Development of next-generation immunomodulatory antibodies for cancer therapy through optimization of the IgG framework. Cancer Cell (2015) 28(3):273-5. doi:10.1016/j.ccell.2015.08.008

26. Jefferis R, Lund J, Pound JD. IgG-FC-mediated effector functions: molecular definition of interaction sites for effector ligands and the role of glycosylation. Immunol Rev (1998) 163(1):59-76. doi:10.1111/j.1600-065X.1998.tb01188.x

27. Lund J, Pound JD, Jones PT, Duncan AR, Bentley T, Goodall M, et al. Multiple binding sites on the ch2 domain of IgG for mouse fcgammar11. Mol Immunol (1992) 29(1):53-9. doi:10.1016/0161-5890(92)90156-R

28. Hart F, Danielczyk A, Goletz S. Human cell line-derived monoclonal IgA antibodies for cancer immunotherapy. Bioengineering (2017) 4(2):42. doi:10.3390/bioengineering 4020042

29. Wang C, Thudium KB, Han M, Wang X-T, Huang H, Feingersh D, et al. In vitro characterization of the anti-PD-1 antibody nivolumab, bms-936558, and in vivo toxicology in non-human primates. Cancer Immunol Res (2014) 2(9):846-56. doi:10.1158/2326-6066.CIR-14-0040

30. Selby MJ, Engelhardt JJ, Quigley M, Henning KA, Chen T, Srinivasan M, et al. Anti-CTLA-4 antibodies of IgG2a isotype enhance antitumor activity through reduction of intratumoral regulatory t cells. Cancer Immunol Res (2013) 1(1):32-42. doi:10.1158/2326-6066.CIR-13-0013

31. Manches O, Lui G, Chaperot L, Gressin R, Molens JP, Jacob MC, et al. In vitro mechanisms of action of rituximab on primary non-Hodgkin lymphomas. Blood (2003) 101(3):949-54. doi:10.1182/blood-2002-02-0469

32. Braig F, Kriegs M, Voigtlaender M, Habel B, Grob T, Biskup K, et al. Cetuximab resistance in head and neck cancer is mediated by EGFR-K521 polymorphism. Cancer Res (2017) 77(5):1188-99. doi:10.1158/0008-5472.CAN-16-0754

33. Weng WK, Levy R. Two immunoglobulin g fragment $\mathrm{c}$ receptor polymorphisms independently predict response to rituximab in patients with follicular lymphoma. J Clin Oncol (2003) 21(21):3940-7. doi:10.1200/JCO.2003.05.013

34. Bibeau F, Lopez-Crapez E, Di Fiore F, Thezenas S, Ychou M, Blanchard F, et al. Impact of Fc $\{$ gamma $\}$ RIIa-Fc $\{$ gamma $\}$ RIIIa polymorphisms and KRAS mutations on the clinical outcome of patients with metastatic colorectal cancer treated with cetuximab plus irinotecan. J Clin Oncol (2009) 27(7):1122-9. doi:10.1200/JCO.2008.18.0463

35. Mossner E, Brunker P, Moser S, Puntener U, Schmidt C, Herter S, et al. Increasing the efficacy of CD20 antibody therapy through the engineering of a new type II anti-CD20 antibody with enhanced direct and immune effector cell-mediated B-cell cytotoxicity. Blood (2010) 115(22):4393-402. doi:10.1182/blood-2009-06-225979

36. Donahue RN, Lepone LM, Grenga I, Jochems C, Fantini M, Madan RA, et al. Analyses of the peripheral immunome following multiple administrations of avelumab, a human IgG1 anti-pd-11 monoclonal antibody. J Immunother Cancer (2017) 5:20. doi:10.1186/s40425-017-0220-y

37. Kumar V, Patel S, Tcyganov E, Gabrilovich DI. The nature of myeloid-derived suppressor cells in the tumor microenvironment. Trends Immunol (2016) 37(3):208-20. doi:10.1016/j.it.2016.01.004

38. Bulliard Y, Jolicoeur R, Windman M, Rue SM, Ettenberg S, Knee DA, et al. Activating Fc $\gamma$ receptors contribute to the antitumor activities of immunoregulatory receptor-targeting antibodies. J Exp Med (2013) 210(9):1685-93. doi:10.1084/jem.20130573

39. Simpson TR, Li F, Montalvo-Ortiz W, Sepulveda MA, Bergerhoff K, Arce F, et al. Fc-dependent depletion of tumor-infiltrating regulatory $\mathrm{T}$ cells codefines the efficacy of anti-CTLA-4 therapy against melanoma. J Exp Med (2013) 210(9):1695-710. doi:10.1084/jem.20130579

40. Bulliard Y, Jolicoeur R, Zhang J, Dranoff G, Wilson NS, Brogdon JL. OX40 engagement depletes intratumoral Tregs via activating Fc $\gamma$ Rs, leading to antitumor efficacy. Immunol Cell Biol (2014) 92(6):475-80. doi:10.1038/ icb. 2014.26

41. Romano E, Kusio-Kobialka M, Foukas PG, Baumgaertner P, Meyer C, Ballabeni P, et al. Ipilimumab-dependent cell-mediated cytotoxicity of regulatory t cells ex vivo by nonclassical monocytes in melanoma patients. Proc Natl Acad Sci U S A (2015) 112(19):6140-5. doi:10.1073/pnas.1417320112

42. Braza MS, Klein B, Fiol G, Rossi JF. $\gamma \delta$ T-cell killing of primary follicular lymphoma cells is dramatically potentiated by GA101, a type II glycoengineered anti-CD20 monoclonal antibody. Haematologica (2011) 96(3):400-7. doi:10.3324/haematol.2010.029520

43. Ochoa MC, Minute L, Rodriguez I, Garasa S, Perez-Ruiz E, Inogés S, et al. Antibody-dependent cell cytotoxicity: immunotherapy strategies enhancing effector NK cells. Immunol Cell Biol (2017) 95(4):347-55. doi:10.1038/ icb. 2017.6

44. Trivedi S, Srivastava RM, Concha-Benavente F, Ferrone S, Garcia-Bates TM, Li J, et al. Anti-EGFR targeted monoclonal antibody isotype influences antitumor cellular immunity in head and neck cancer patients. Clin Cancer Res (2016) 22(21):5229-37. doi:10.1158/1078-0432.CCR-15-2971

45. Srivastava RM, Trivedi S, Concha-Benavente F, Gibson SP, Reeder C, Ferrone S, et al. Cd137 stimulation enhances cetuximab-induced natural killer: dendritic cell priming of antitumor T-cell immunity in patients with head and neck cancer. Clin Cancer Res (2017) 23(3):707-16. doi:10.1158/1078-0432. CCR-16-0879

46. Caccamo N, Sireci G, Meraviglia S, Dieli F, Ivanyi J, Salerno A. Gammadelta $\mathrm{T}$ cells condition dendritic cells in vivo for priming pulmonary CD8 $\mathrm{T}$ cell responses against mycobacterium tuberculosis. Eur JImmumol (2006) 36(10):2681-90. doi:10.1002/eji.200636220

47. Zhao X, Rajasekaran N, Reusch U, Marschner J-P, Treder M, Kohrt HE. Cd137 co-stimulation and blocking PD-1 enhances NK cell-mediated target cell lysis by CD30/CD16a TandAb AFM13. J Clin Oncol (2015) 33(15_suppl):3050-3050. doi:10.1200/jco.2015.33.15_suppl.3050

48. Guo Y, Feng X, Jiang Y, Shi X, Xing X, Liu X, et al. PD1 blockade enhances cytotoxicity of in vitro expanded natural killer cells towards myeloma cells. Oncotarget (2016) 7(30):48360. doi:10.18632/oncotarget.10235

49. Lehrnbecher T, Foster CB, Zhu S, Leitman SF, Goldin LR, Huppi K, et al. Variant genotypes of the low-affinity fcgamma receptors in two control populations and a review of low-affinity fcgamma receptor polymorphisms in control and disease populations. Blood (1999) 94(12):4220-32.

50. Iwai Y, Hamanishi J, Chamoto K, Honjo T. Cancer immunotherapies targeting the PD-1 signaling pathway. J Biomed Sci (2017) 24(1):26. doi:10.1186/ s12929-017-0329-9

Conflict of Interest Statement: CG, TL, UH, PS, AD, JR, and SG are/were employed by and $\mathrm{AD}$ and $\mathrm{SG}$ are shareholders of Glycotope $\mathrm{GmbH}$.

Copyright $\odot 2018$ Goletz, Lischke, Harnack, Schiele, Danielczyk, Rühmann and Goletz. This is an open-access article distributed under the terms of the Creative Commons Attribution License (CC BY). The use, distribution or reproduction in other forums is permitted, provided the original author(s) and the copyright owner(s) are credited and that the original publication in this journal is cited, in accordance with accepted academic practice. No use, distribution or reproduction is permitted which does not comply with these terms. 